\title{
Complex hybridity in Isotoma petraea. VIII. Variation for seed aborting lethal genes in the $\bigcirc 6$ Pigeon Rock population
}

\author{
S. H. JAMES, J. PLAYFORD* \& J. F. SAMPSON $\dagger$ \\ Botany Department, The University of Western Australia, Nedlands, 6009, Western Australia
}

\begin{abstract}
The highly inbreeding Pigeon Rock population of Isotoma petraea consists of about one-third primitive structural homozygotes and two-thirds derived ring-of-six (or ring-of-ten) complex heterozygotes. A majority of the structural homozygotes exhibit significant proportions of seed abortion in their selfed capsules, ranging from about 1 to 33.8 per cent, while all the structural heterozygotes exhibit significant levels of seed abortion, ranging from 8.8 to 59.9 per cent. Seed abortion ratios appear to be determined by genic interactions which are sensitive to plant growth conditions. It is suggested that seed aborting recessive lethal genes are of adaptive utility and have accumulated in this population because they prevent the allocation of resources to inbred homozygotes, which cannot contribute to future generations. The seed aborting systems may be modelled in terms of recessive seed-aborting lethal genes and independently assorting dominant modifiers of those genes. Appropriate mutations may be generated by the transposition of internal chromosome segments.
\end{abstract}

Keywords: complex heterozygotes, multiple interchange, seed abortion.

\section{Introduction}

Complex hybridity is a genetic system which combines autogamy, multiple interchange hybridity and a balanced lethal system. In Isotoma petraea the genetic system apparently first became established at Pigeon Rock, a large granite outcrop some $100 \mathrm{~km}$ north of Southern Cross in Western Australia (James, 1965, 1970). At the present time, this population exhibits a fairly stable polymorphism of approximately twothirds ring-of-six (O6) complex heterozygotes and onethird structural homozygotes (7IIs) plus a very low proportion (1.1 per cent) of ring-of-ten (O10) complex heterozygotes (James et al., 1990). The population also exhibits considerable variation in seed abortion behaviour, which suggests that information concerning the evolutionary assembly of the balanced lethal system may be available here.

In this paper, variation in seed abortion behaviour existing in the Pigeon Rock population and in progeny

*Present address: Molecular and Population Genetics Group, Research School of Biological Sciences, The Australian National University, Canberra, A.C.T., 2601, Australia.

†Present address: Horticultural Sciences, School of Biological and Environmental Sciences, Murdoch University, Murdoch, 6150, Western Australia. analyses is described. We conclude that seed aborting recessive lethal genes accumulated in the nascent complex hybrid lineages in this population subsequent to the origin of interchange heterozygosity. They may have had an adaptive use in preventing the allocation of resources to deleteriously homozygous inbred progeny.

\section{Materials and methods}

Rootstocks were collected from Pigeon Rock and grown under 15 - $\mathrm{h}$ day conditions in a glasshouse at The University of Western Australia. The regenerated plants grew strongly but deteriorated after about 6 months growth. They were then reinvigorated by pruning and the application of fertilizer.

Isotoma is of the Family Lobeliaceae and is characterized by the fusion of the anthers to form a tube which encloses the immature stigma and style. Self pollination occurred automatically in flowers in which the stigma did not protrude from the anther tube. Controlled cross-pollinations were conducted using emasculated flowers covered with short waxed drinking straws as females.

Mature capsules were harvested and allowed to dry out in vials plugged with cotton wool. The entire contents of individual capsules were then dissected into 
porcelain dishes and sorted with the aid of a dissecting microscope. The capsules included fully formed 'good' seeds, aborted seeds in which the testa was either clearly developed ('late death') or apparently undifferentiated ('early death'), and 'white chaff', which consisted of unfertilized ovules and sterile ovules that had aborted due to meiotic irregularities. Previous studies (Beltran \& James, 1970; Beltran, 1971) have indicated that the discrimination between early and late death phenotypes is less reliable with superficial microscopy but is highly reliable in serial sectioned material. Serial sectioning was not used in this study. All the good and aborted seeds were counted for each capsule examined but the white chaff was ignored.

Two capsules from each of 55 plants were counted to assess seed abortion ratios in the population survey. Fifteen of the plants exhibited significant heterogeneity between capsules $\left(\chi_{(1)}^{2}>3.84 ; P<0.05\right)$, nine of them yielding $\chi_{(1)}^{2}>6.64 ; P<0.01$. The latter nine plants were resampled. In seven of these, the third capsule proved to be homogeneous with one of the original samples, while in two, the third and fourth capsules sampled were homogeneous. The seed abortion ratio was calculated as the mean percentage of aborted seeds in the two homogeneous capsules.

The seed abortion behaviour of one plant (O6PR16), which exhibited significant heterogeneity between capsules, was examined in relation to its general growth state. An initial collection of four capsules from this plant had been made towards the end of the first vigorous growth phase. A series of 24 capsules from vigorously growing branches, which developed following pruning and the application of fertilizer, and six capsules from that growth as it later deteriorated were analysed.

PGM allozyme genotypes in a sample of selfed seeding progenies of usually 20 plants each were determined using starch gel electrophoretic techniques described previously (James et al., 1983). The sample was from 18 plants of the 1987 collection and 10 collected previously (1983). The progenies were scored at about the four-leafed seedling stage. It has been shown previously (James et al., 1990) that the interchange heterozygotes in the population may be regarded as NS complex hybrids in which $\mathbf{N}$ is a complex marked by PGM3, generally pollen nontransmissible and never found in the homozygous condition. $\mathbf{S}$ is a complex of primitive chromosome end sequence two interchanges removed from $\mathbf{N}$, marked by PGM1 or PGM2 and freely transmissible in both pollen and embryosac.

Two 06 complex heterozygotes, O6PR11 and O6PR55 were intercrossed and crossed to structural homozygotes from Yackeyackine Soak (also known as
'495') in order to observe seed abortion phenotypes following cross pollination and in progeny plants. The ' 495 ' plants were entirely seed fertile.

\section{Observations}

The capsule contents from 55 plants of the 1987 collection are presented in Table 1 . Significant variation occurred in respect of the total number of good plus aborted seed within the first two capsules scored per plant, $F_{(54,55)}=7.035 ; P<0.001$, but most of the variation was between cytotypes (Table 2 ). The average number of seeds per capsule was 784.4 for 7IIs, 555.3 for O6s and 329.4 for O10s. That is, the O6s and the 010 s exhibited 0.71 and 0.42 times the seed numbers of the 7IIs. These coefficients may be taken to reflect the frequencies of meiotic disjunction in $06 \mathrm{~s}$ and $\mathrm{O} 10 \mathrm{~s}$, respectively, and generally conform with previous estimates (James, 1970). There is no evidence that the cytotypes in this population differ with respect to absolute ovule numbers. As there is an abundance of pollen available in automatically self pollinated flowers, there is no reason to suppose that deficient

Table 1 Capsule contents from each of 55 Pigeon Rock plants collected in 1987. The number of capsules scored was such as to provide two capsules with a heterogeneity $\chi_{(1)}^{2}$ value less than 6.64 with respect to the seed abortion ratio

\begin{tabular}{|c|c|c|c|c|c|}
\hline $\begin{array}{l}\text { Plant } \\
\text { number }\end{array}$ & $\begin{array}{l}\text { Capsule } \\
\text { number }\end{array}$ & $\begin{array}{l}\text { Good } \\
\text { seeds }\end{array}$ & $\begin{array}{l}\text { Aborted } \\
\text { seeds }\end{array}$ & $\chi_{(1)}^{2} P$ & $\begin{array}{l}\text { Seed } \\
\text { abortio } \\
(\%)\end{array}$ \\
\hline \multicolumn{6}{|l|}{ 7IIs } \\
\hline \multirow[t]{2}{*}{39} & 1 & 855 & 4 & $0.00 \mathrm{~ns}$ & 0.47 \\
\hline & 2 & 835 & 4 & & \\
\hline \multirow[t]{2}{*}{45} & 1 & 815 & 5 & $0.05 \mathrm{~ns}$ & 0.57 \\
\hline & 2 & 575 & 3 & & \\
\hline \multirow[t]{2}{*}{53} & 1 & 848 & 7 & $0.46 \mathrm{~ns}$ & 0.68 \\
\hline & 2 & 900 & 5 & & \\
\hline \multirow[t]{2}{*}{34} & 1 & 1000 & 11 & $4.83^{*}$ & 0.68 \\
\hline & 2 & 1036 & 3 & & \\
\hline \multirow[t]{2}{*}{38} & 1 & 989 & 7 & $0.10 \mathrm{~ns}$ & 0.76 \\
\hline & 2 & 960 & 8 & & \\
\hline \multirow[t]{2}{*}{46} & 1 & 814 & 9 & $2.42 \mathrm{~ns}$ & 0.77 \\
\hline & 2 & 737 & 3 & & \\
\hline \multirow[t]{2}{*}{41} & 1 & 985 & 5 & $2.07 \mathrm{~ns}$ & 0.78 \\
\hline & 2 & 911 & 10 & & \\
\hline \multirow[t]{2}{*}{58} & 1 & 627 & 5 & $0.51 \mathrm{~ns}$ & 0.99 \\
\hline & 2 & 668 & 8 & & \\
\hline \multirow[t]{2}{*}{36} & 1 & 798 & 15 & $2.72 \mathrm{~ns}$ & 1.36 \\
\hline & 2 & 867 & 8 & & \\
\hline \multirow[t]{4}{*}{2} & $1^{*}$ & 594 & 238 & $124.05^{* * *}$ & 1.74 \\
\hline & $2^{*}$ & 661 & 46 & & \\
\hline & 3 & 928 & 16 & & \\
\hline & 4 & 820 & 15 & & \\
\hline
\end{tabular}


Table 1 - Continued

\begin{tabular}{|c|c|c|c|c|c|}
\hline $\begin{array}{l}\text { Plant } \\
\text { number }\end{array}$ & $\begin{array}{l}\text { Capsule } \\
\text { number }\end{array}$ & $\begin{array}{l}\text { Good } \\
\text { seeds }\end{array}$ & $\begin{array}{l}\text { Aborted } \\
\text { seeds }\end{array}$ & $\chi_{(1)}^{2} P$ & $\begin{array}{l}\text { Seed } \\
\text { abortion } \\
(\%)\end{array}$ \\
\hline \multirow[t]{2}{*}{21} & 1 & 842 & 13 & $2.76 \mathrm{~ns}$ & 2.10 \\
\hline & 2 & 879 & 24 & & \\
\hline \multirow[t]{2}{*}{49} & 1 & 650 & 10 & $3.33 \mathrm{~ns}$ & 2.36 \\
\hline & 2 & 1043 & 31 & & \\
\hline \multirow[t]{2}{*}{43} & 1 & 586 & 17 & $0.99 \mathrm{~ns}$ & 2.42 \\
\hline & 2 & 423 & 8 & & \\
\hline \multirow[t]{2}{*}{14} & 1 & 605 & 16 & $0.13 \mathrm{~ns}$ & 2.42 \\
\hline & 2 & 562 & 13 & & \\
\hline \multirow[t]{2}{*}{8} & 1 & 716 & 34 & $5.98^{*}$ & 6.03 \\
\hline & 2 & 686 & 56 & & \\
\hline \multirow[t]{2}{*}{35} & 1 & 571 & 106 & $2.74 \mathrm{~ns}$ & 17.37 \\
\hline & 2 & 561 & 132 & & \\
\hline \multirow[t]{3}{*}{40} & 1 & 394 & 90 & $11.28^{* * *}$ & 17.60 \\
\hline & $2^{*}$ & 528 & 195 & & \\
\hline & 3 & 552 & 112 & & \\
\hline \multirow[t]{2}{*}{26} & 1 & 556 & 156 & $2.43 \mathrm{~ns}$ & 23.63 \\
\hline & 2 & 491 & 168 & & \\
\hline \multirow[t]{3}{*}{28} & $1^{*}$ & 495 & 233 & $6.79^{*}$ & 25.78 \\
\hline & 2 & 572 & 200 & & \\
\hline & 3 & 640 & 221 & & \\
\hline \multirow[t]{2}{*}{20} & 1 & 492 & 196 & $4.33^{*}$ & 25.95 \\
\hline & 2 & 598 & 186 & & \\
\hline \multirow[t]{2}{*}{27} & 1 & 626 & 218 & $0.02 \mathrm{~ns}$ & 25.99 \\
\hline & 2 & 667 & 236 & & \\
\hline \multirow[t]{2}{*}{23} & 1 & 601 & 211 & $0.13 \mathrm{~ns}$ & 26.37 \\
\hline & 2 & 538 & 197 & & \\
\hline \multirow[t]{2}{*}{19} & 1 & 493 & 223 & $3.96^{*}$ & 33.77 \\
\hline & 2 & 574 & 321 & & \\
\hline \multicolumn{6}{|l|}{ O6s } \\
\hline \multirow[t]{2}{*}{22} & 1 & 511 & 44 & $1.15 \mathrm{~ns}$ & 8.81 \\
\hline & 2 & 441 & 48 & & \\
\hline \multirow[t]{2}{*}{42} & 1 & 528 & 66 & $0.60 \mathrm{~ns}$ & 10.45 \\
\hline & 2 & 466 & 50 & & \\
\hline \multirow[t]{2}{*}{13} & 1 & 451 & 56 & $0.24 \mathrm{~ns}$ & 11.53 \\
\hline & 2 & 439 & 60 & & \\
\hline \multirow[t]{3}{*}{30} & $1^{*}$ & 655 & 46 & $8.80^{* *}$ & 13.12 \\
\hline & 2 & 477 & 61 & & \\
\hline & 3 & 311 & 58 & & \\
\hline \multirow[t]{2}{*}{48} & 1 & 331 & 56 & $0.52 \mathrm{~ns}$ & 13.48 \\
\hline & 2 & 548 & 81 & & \\
\hline \multirow[t]{2}{*}{47} & 1 & 452 & 66 & $5.55^{*}$ & 15.21 \\
\hline & 2 & 334 & 75 & & \\
\hline 54 & 1 & 283 & 77 & $3.55 \mathrm{~ns}$ & 18.57 \\
\hline & 2 & 344 & 66 & & \\
\hline 50 & 1 & 276 & 174 & $1.23 \mathrm{~ns}$ & 40.44 \\
\hline & 2 & 238 & 175 & & \\
\hline 51 & $1^{*}$ & 258 & 262 & $8.43^{* *}$ & 43.40 \\
\hline & 2 & 259 & 180 & & \\
\hline & 3 & 281 & 234 & & \\
\hline 1 & 1 & 260 & 191 & $1.59 \mathrm{~ns}$ & 44.51 \\
\hline & 2 & 281 & 243 & & \\
\hline
\end{tabular}

Table 1 - Continued

\begin{tabular}{|c|c|c|c|c|c|}
\hline $\begin{array}{l}\text { Plant } \\
\text { number }\end{array}$ & $\begin{array}{l}\text { Capsule } \\
\text { number }\end{array}$ & $\begin{array}{l}\text { Good } \\
\text { seeds }\end{array}$ & $\begin{array}{l}\text { Aborted } \\
\text { seeds }\end{array}$ & $\chi_{(1)}^{2} P$ & $\begin{array}{l}\text { Seed } \\
\text { abortion } \\
(\%)\end{array}$ \\
\hline \multirow[t]{2}{*}{57} & 1 & 358 & 303 & $0.37 \mathrm{~ns}$ & 45.07 \\
\hline & 2 & 277 & 218 & & \\
\hline \multirow[t]{2}{*}{9} & 1 & 286 & 249 & $0.36 \mathrm{~ns}$ & 45.60 \\
\hline & 2 & 326 & 264 & & \\
\hline \multirow[t]{2}{*}{37} & 1 & 412 & 354 & $0.29 \mathrm{~ns}$ & 45.62 \\
\hline & 2 & 258 & 208 & & \\
\hline \multirow[t]{2}{*}{25} & 1 & 344 & 277 & $1.20 \mathrm{~ns}$ & 46.26 \\
\hline & 2 & 432 & 391 & & \\
\hline \multirow[t]{2}{*}{24} & 1 & 294 & 259 & $0.00 \mathrm{~ns}$ & 46.82 \\
\hline & 2 & 250 & 220 & & \\
\hline \multirow[t]{2}{*}{33} & 1 & 268 & 254 & $0.96 \mathrm{~ns}$ & 47.16 \\
\hline & 2 & 272 & 228 & & \\
\hline \multirow[t]{2}{*}{11} & 1 & 316 & 247 & $5.65^{*}$ & 47.37 \\
\hline & 2 & 265 & 276 & & \\
\hline \multirow[t]{2}{*}{31} & 1 & 289 & 269 & $0.30 \mathrm{~ns}$ & 47.39 \\
\hline & 2 & 305 & 266 & & \\
\hline \multirow[t]{2}{*}{7} & 1 & 276 & 267 & $0.49 \mathrm{~ns}$ & 48.06 \\
\hline & 2 & 340 & 303 & & \\
\hline \multirow[t]{2}{*}{3} & 1 & 323 & 294 & $0.11 \mathrm{~ns}$ & 48.12 \\
\hline & 2 & 312 & 295 & & \\
\hline \multirow[t]{4}{*}{56} & $1^{*}$ & 487 & 329 & $135.94^{* * *}$ & 48.66 \\
\hline & $2^{*}$ & 181 & 447 & & \\
\hline & 3 & 270 & 265 & & \\
\hline & 4 & 303 & 278 & & \\
\hline \multirow[t]{2}{*}{44} & 1 & 256 & 246 & $0.01 \mathrm{~ns}$ & 48.87 \\
\hline & 2 & 240 & 228 & & \\
\hline \multirow[t]{2}{*}{32} & 1 & 221 & 234 & $2.32 \mathrm{~ns}$ & 48.87 \\
\hline & 2 & 256 & 222 & & \\
\hline \multirow[t]{2}{*}{17} & 1 & 256 & 257 & $0.47 \mathrm{~ns}$ & 49.01 \\
\hline & 2 & 286 & 264 & & \\
\hline \multirow[t]{2}{*}{4} & 1 & 384 & 393 & $1.21 \mathrm{~ns}$ & 49.16 \\
\hline & 2 & 433 & 397 & & \\
\hline \multirow[t]{2}{*}{12} & 1 & 294 & 302 & $0.02 \mathrm{~ns}$ & 50.86 \\
\hline & 2 & 306 & 319 & & \\
\hline \multirow[t]{3}{*}{16} & $1^{*}$ & 302 & 448 & $7.40^{* *}$ & 51.28 \\
\hline & 2 & 387 & 435 & & \\
\hline & 3 & 414 & 408 & & \\
\hline \multirow[t]{2}{*}{6} & 1 & 355 & 388 & $0.62 \mathrm{~ns}$ & 51.32 \\
\hline & 2 & 233 & 232 & & \\
\hline \multirow[t]{3}{*}{55} & 1 & 181 & 214 & $4.88^{*}$ & 53.28 \\
\hline & $2^{*}$ & 196 & 168 & & \\
\hline & 3 & 254 & 282 & & \\
\hline \multirow[t]{2}{*}{29} & 1 & 199 & 291 & $0.10 \mathrm{~ns}$ & 59.88 \\
\hline & 2 & 207 & 315 & & \\
\hline \multicolumn{6}{|l|}{ O10s } \\
\hline 10 & $1^{*}$ & 148 & 183 & $77.78^{* * *}$ & 23.26 \\
\hline & 2 & 284 & 84 & & \\
\hline & 3 & 224 & 70 & & \\
\hline 18 & 1 & 308 & 43 & $0.06 \mathrm{~ns}$ & 12.54 \\
\hline & 2 & 264 & 39 & & \\
\hline
\end{tabular}

*Capsules judged to be deviant. 
pollination contributed to any pre-zygotic limitation of seed numbers in selfed capsules.

Heterogeneity between the first two capsules scored for seed abortion patterns was significant in 15 of the 55 plants sampled. An analysis of variance over these capsules demonstrated that the variation between plants was highly significant relative to the variation between capsules within plants $\left(F_{(54,55)}=29.04\right.$; $P<0.001$; Table 3$)$. The analysis of 34 capsules from O6PR16 is summarized in Fig. 1. Four capsules

Table 2 Analysis of variance of seed numbers per capsule showing significant variation between plants and between cytotypes

\begin{tabular}{lrrrr}
\hline & & & $\begin{array}{l}\text { Unbiased } \\
\text { estimates } \\
\text { of variance } \\
\text { components }\end{array}$ \\
$\begin{array}{lrrrr}\text { Source of } \\
\text { variation }\end{array}$ & $\begin{array}{l}\text { Degrees of } \\
\text { freedom }\end{array}$ & $\begin{array}{l}\text { Sums of } \\
\text { squares }\end{array}$ & $\begin{array}{l}\text { Mean } \\
\text { squares }\end{array}$ & \\
\hline $\begin{array}{l}\text { Cytotypes } \\
\text { Plants }\end{array}$ & 52 & 1688200 & 844100 & 28297.3 \\
Capsules & 55 & 1301200 & 25023.1 & 8576.9 \\
\hline
\end{tabular}

Table 3 Analysis of variance of percentage seed abortion in capsules showing significant variation between plants

\begin{tabular}{llcc}
\hline $\begin{array}{l}\text { Source of } \\
\text { variation }\end{array}$ & $\begin{array}{l}\text { Degrees of } \\
\text { freedom }\end{array}$ & $\begin{array}{l}\text { Sums of } \\
\text { squares }\end{array}$ & $\begin{array}{l}\text { Mean } \\
\text { squares }\end{array}$ \\
\hline Plants & 54 & 44691.5 & 827.6 \\
Capsules & 55 & 1568.4 & 28.5 \\
\hline
\end{tabular}

harvested from deteriorating growth, just before the plant was reinvigorated by pruning and the application of fertilizer, yielded significantly heterogenous seed abortion estimates of $59.7,52.9,49.6$ and 78.8 per cent, respectively $\left(\chi_{(3)}^{2}=167.5 ; P<0.001\right)$. Twenty-four capsules collected from vigorous new growth gave much more consistent results $\left(\chi_{(23)}^{2}=30.3\right.$, ns). Six capsules collected as the branches again approached senescence exhibited significant heterogeneity $\left(\chi_{(5)}^{2}=71.8 ; P<0.001\right)$. While these results indicate an environmental component in the determination of seed abortion ratio, the consistency of the ratio in capsules developed under vigorous or non-stressed growth conditions indicates that the seed abortion ratio is a characteristic attribute of the plant, most of the variation is genetically determined, and the population is polymorphic for seed-aborting genes.

In order to reduce the effects of environmental variation, seed abortion estimates were based on pairs of comparable capsules selected such that their heterogeneity $\chi_{(1)}^{2}$ value did not exceed 6.64. Eight of the 23 structural homozygotes (7IIs) sampled had little or no seed abortion (less than 1 per cent) with the remainder ranging from 1.4 to 33.8 per cent. On the other hand, all the O6s exhibited significant levels of seed abortion, ranging from 8.8 to 59.9 per cent and usually just less than 50 per cent. The two 010 s examined exhibited 12.5 per cent and 23.3 per cent seed abortion, respectively.

The selfed capsule seed abortion frequencies for 26 O6 and two 010 plants, along with a PGM genotype analysis of a sample of usually 20 four-leaf stage seedlings from each, is presented in Table 4. The rela-

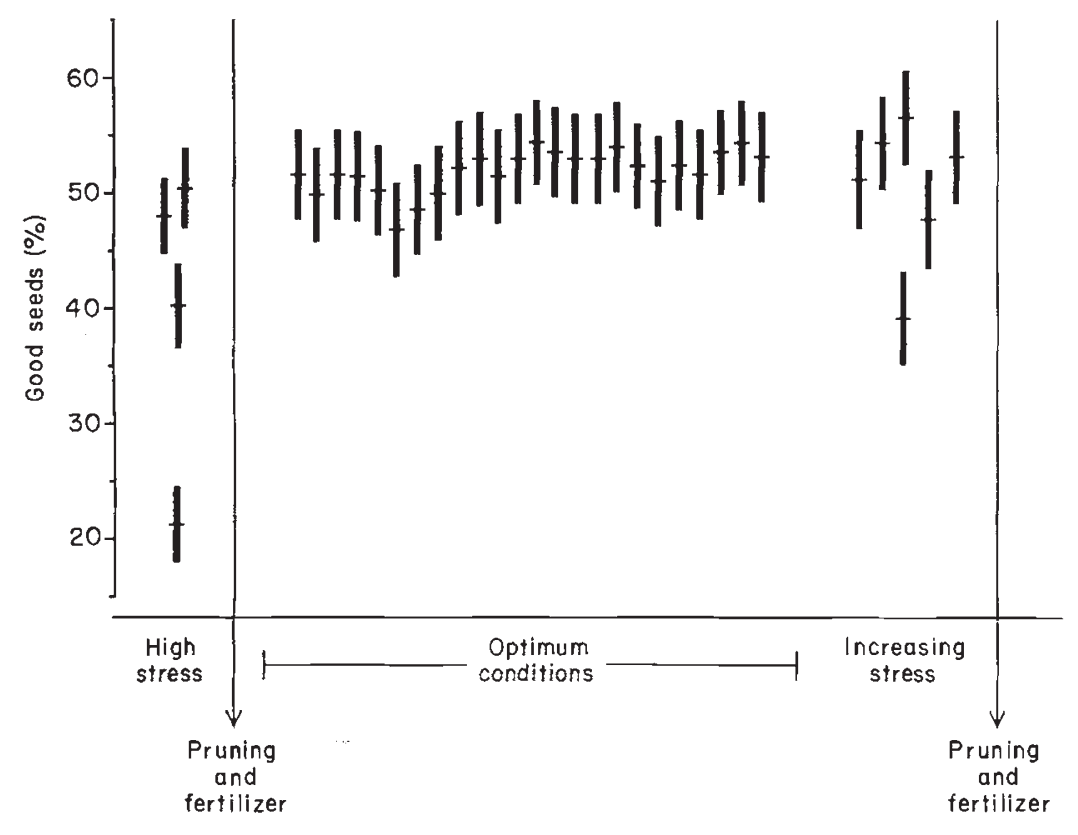

Fig. 1 Percentage seed fertility in 34 self-pollinated capsules from O6PR16. The bars indicate the 95 per cent confidence interval of the estimate, for individual capsules which developed under conditions of relative stress (left and right) and non-stress (centre). Apart from the major groupings indicated, the positions of the bars do not indicate any harvest sequence within groups. 
Table 4 Raw data showing the proportion of SS homozygotes, detected as genotypes free of PGM3, and the seed abortion frequencies of 28 Pigeon Rock O6 plants

\begin{tabular}{|c|c|c|c|}
\hline \multirow{2}{*}{$\begin{array}{l}\text { Plant } \\
\text { number }\end{array}$} & \multicolumn{2}{|c|}{$\begin{array}{l}\text { Number of selfed } \\
\text { progeny having } \\
\text { PGM genotype }\end{array}$} & \multirow{2}{*}{$\begin{array}{l}\text { Seed } \\
\text { abortion } \\
(\%)\end{array}$} \\
\hline & $3 / *$ & $* / *$ & \\
\hline $83 / 4$ & 20 & - & 49.49 \\
\hline $83 / 6$ & 20 & - & 47.55 \\
\hline $83 / 22$ & 20 & - & 46.29 \\
\hline $83 / 32$ & 15 & 5 & 24.7 \\
\hline $83 / 33$ & 12 & 8 & 4.89 \\
\hline $83 / 42 a$ & 18 & 2 & 7.57 \\
\hline $83 / 82$ & 10 & 10 & 12.13 \\
\hline $83 / 100$ & 10 & - & 47.91 \\
\hline $83 / 122$ & 20 & - & 37.76 \\
\hline $83 / 125$ & 19 & 1 & 46.37 \\
\hline 1 & 20 & - & 44.51 \\
\hline 6 & 11 & - & 51.32 \\
\hline 7 & 30 & - & 48.06 \\
\hline 10 & 14 & 6 & 23.26 \\
\hline 11 & 32 & - & 47.37 \\
\hline 13 & 21 & 4 & 11.53 \\
\hline 16 & 29 & - & 51.28 \\
\hline 18 & 9 & 11 & 12.54 \\
\hline 22 & 8 & 13 & 8.81 \\
\hline 30 & 10 & 19 & 13.12 \\
\hline 33 & 20 & - & 47.16 \\
\hline 37 & 12 & - & 45.62 \\
\hline 42 & 16 & 5 & 10.45 \\
\hline 44 & 20 & - & 48.87 \\
\hline 47 & 9 & 6 & 15.21 \\
\hline 48 & 9 & 1 & 13.48 \\
\hline 50 & 20 & - & 40.44 \\
\hline 54 & 13 & 2 & 18.57 \\
\hline
\end{tabular}

' 83 ' indicates plants collected in 1983, the remainder collected in 1987.

tionship between the genotypic composition of the selfed progeny and the seed abortion frequency of the parent is illustrated in Fig. 2. The PGM $3 / *$ and ** genotypes correspond to NS and SS complex combinations respectively (see above). It can be seen that the proportion of $\mathbf{S S}$ homozygotes recovered, $y$, was related to the level of seed abortion, $x$, as $y=0.4639-0.9738 x$. As the O6 complex heterozygotes at Pigeon Rock are highly self pollinating and normally do not transmit the $\mathbf{N}$ complex through the pollen, this genetic system should yield heterozygotes and homozygotes in equal frequencies. The observed regression line, relating the proportion of $\mathbf{S S}$ progeny recovered in selfed progenies, $y$, with the seed abortion frequency, $x$, is very close to the theoretical expecta-

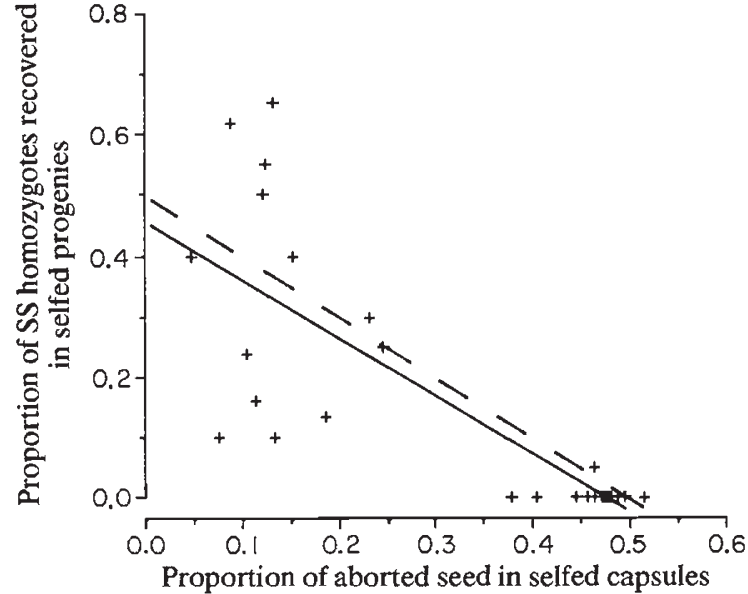

Fig. 2 Relationship between the proportion of SS homozygotes, detected as genotypes free of PGM3, in selfed progenies and the seed abortion frequency of parental plants. The calculated regression line (solid) and the theoretical regression line (broken) assuming all seed abortion is due to the abortion of SS zygotes are shown.

tion, $y=0.5-x$ (Fig. 2) describing the situation in which all seed abortion is attributable to SS homozygote elimination $\left(H_{0}: b=-1 ; s_{\mathrm{b}}=0.14862 ; t=0.176\right.$; $P>0.8$ ). This strongly supports the hypothesis that in the structural heterozygotes the seed abortion mechanism results in a preferential elimination of the SS homozygotes.

Capsule contents and seed abortion frequencies for a variety of materials derived from O6PR11, O6PR55 and 711495 are presented in Table 5. While there was some heterogeneity between similarly produced capsules, there were highly significant differences between the groups of capsules of common parentage relative to the variation between capsules within those groups.

The seed abortion frequencies in two 06 selfed progeny plants of O6PR 11 (mean 48.4 per cent) were quite comparable to that of the parent (mean 47.4 per cent). No SS homozygotes were recovered amongst 32 four-leaf stage selfed progeny of O6PR11 (Table 4). These observations conform with the hypothesis that such 06 s are complex hybrids which transmit their genotypes essentially unchanged to their selfed progeny.

The seed abortion frequencies were quite unequal in the reciprocal O6PR $11 \times$ O6PR55 crossed capsules and significantly less (mean 16.1 per cent) than in the selfed capsules of the complex hybrid parents (mean 50.3 per cent). This indicates that the seed-aborting lethal systems associated with the $\mathbf{S}$ complex differ between plants within the population and that $\mathbf{S}$ complexes from different plants have the capacity to com- 
Table 5 Raw data and percentage seed abortion in capsules variously derived from O6PR11, O6PR55 and 7II495 (Yackeyackine Soak)

\begin{tabular}{|c|c|c|c|c|}
\hline \multirow[b]{2}{*}{$\begin{array}{l}\text { Group } \\
\text { number }\end{array}$} & \multirow[b]{2}{*}{ Ancestry of capsule } & \multicolumn{2}{|c|}{ Capsule contents } & \multirow{2}{*}{$\begin{array}{l}\text { Seed } \\
\text { abortion } \\
(\%)\end{array}$} \\
\hline & & $\begin{array}{l}\text { Good } \\
\text { seeds }\end{array}$ & $\begin{array}{l}\text { Aborted } \\
\text { seeds }\end{array}$ & \\
\hline \multirow[t]{2}{*}{1} & \multirow{2}{*}{ O6(O6PR $11 \otimes) \mathrm{a} \otimes$} & 211 & 227 & \multirow{2}{*}{48.8} \\
\hline & & 249 & 212 & \\
\hline 2 & 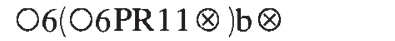 & 287 & 265 & 48.0 \\
\hline 3 & O6PR55×06PR1 1 & 366 & 24 & 6.2 \\
\hline 4 & O6PR11×O6PR55 & 324 & 114 & 26.0 \\
\hline \multirow[t]{2}{*}{5} & \multirow{2}{*}{$7 \mathrm{II}($ O6PR $11 \times$ O6PR55) $\otimes$} & 335 & 196 & \multirow{2}{*}{37.5} \\
\hline & & 435 & 266 & \\
\hline \multirow[t]{3}{*}{6} & \multirow[t]{3}{*}{ O6(O6PR11× O6PR55)® } & 229 & 189 & \multirow[t]{3}{*}{48.3} \\
\hline & & 194 & 197 & \\
\hline & & 184 & 182 & \\
\hline \multirow[t]{2}{*}{7} & \multirow[t]{2}{*}{ O6PR11 × 7II495 } & 374 & 34 & \multirow[t]{2}{*}{7.3} \\
\hline & & 378 & 25 & \\
\hline \multirow[t]{2}{*}{8} & \multirow[t]{2}{*}{$7 \mathrm{II}(\mathrm{O} 6 \mathrm{PR} 11 \times 7 \mathrm{II} 495) \otimes$} & 508 & 105 & \multirow[t]{2}{*}{17.9} \\
\hline & & 500 & 114 & \\
\hline \multirow[t]{2}{*}{9} & \multirow[t]{2}{*}{$7 \mathrm{II}($ O6PR $55 \times 7 \mathrm{II} 495) \otimes$} & 599 & 30 & \multirow[t]{2}{*}{3.9} \\
\hline & & 532 & 16 & \\
\hline \multirow[t]{2}{*}{10} & \multirow[t]{2}{*}{ O6 $($ O6PR $11 \times 7 \mathrm{II} 495) \otimes$} & 191 & 5 & \multirow[t]{2}{*}{7.4} \\
\hline & & 482 & 49 & \\
\hline
\end{tabular}

plement each other partially. An SS homozygote obtained from this cross exhibited 37.5 per cent seed abortion while a heterozygote, which combined $\mathbf{N}$ from O6PR11 and $\mathbf{S}$ from O6PR55, exhibited 48.3 per cent seed abortion, a level comparable with the parents. These results demonstrate that the seed abortion system is most efficient when $\mathbf{S}$ is associated with an $\mathbf{N}$, irrespective of the source of the latter. Presumably, the linkage associated with the interchange hybridity in NS heterozygotes elevates the efficiency of SS homozygote elimination.

In addition, O6PR $11 \times 7 \mathrm{II} 495$ crossed capsules exhibited a much reduced seed abortion frequency (mean 7.3 per cent). Thus, the ' 495 ' genome carried alleles dominant to the seed-aborting recessive lethals associated with the $\mathbf{S}$ complex. Synthetic hybrids combining '495' genomes with $\mathbf{S}$ complexes from the two different complex hybrids exhibited low but distinctly different levels of seed abortion (3.9 and 17.9 per cent). This again indicates significant genetic differences between the different complex hybrids. The synthetic O6 combining a genome containing the pollen nontransmissible $\mathbf{N}$ from O6PR11 with a lethal free '495' genome exhibited a significant but low level of seed abortion (7.4 per cent). This indicates that chromosomes outside the ring in the $\bigcirc 6$ complex hybrids must also carry recessive lethal factors.

\section{Discussion}

The seed abortion frequencies in both the structurally homozygous and complex hybrid components of the Pigeon Rock population are genetically determined but environmental factors may elevate abortion over the genetically determined levels. The seed-abortion mechanism preferentially removes SS homozygotes from the selfed progenies. If the $\mathbf{S S}$ homozygotes are otherwise genetically incompetent, because of homozygosity for deleterious recessives which act after seed formation, then the seed-aborting system would be adaptive in reducing maternal investment into incompetent offspring.

The Pigeon Rock population is highly inbreeding and must be composed of autogamic lineages essentially isolated from each other. At the same time, however, rare cross pollination events are possible so that the population may have some of the genetic reticulation characteristic of outbreeding populations. Divergence between lineages within the population may have resulted from the accumulation of mutations that occur independently within lineages. On the other hand, rare crossings between these lineages may have established new lineages. Thus, the 7II component of the population may receive inputs of SS structural homozygotes from selfed NS plants with incomplete SS abortion and from rare crosses between divergent complex 
heterozygotes. Such 7IIs exhibit significant levels of seed abortion, but less than that associated with the $\mathbf{S}$ complexes in most NS heterozygotes. In addition, rare crosses between $06 \mathrm{~s}$ and 7 IIs may combine $\mathbf{N}$ complexes with genomes essentially free of seed aborting lethals to yield complex hybrids with low levels of seed abortion. These new lineages may then proceed to differentiate by the accumulation of mutations increasing the efficiency of the seed-aborting system.

The assembly of 06 complex hybridity on Pigeon Rock appears to have involved the origin of the pollen non-transmissible $\mathbf{N}$ complex, its elevation to high frequencies under essentially autogamous conditions, and the development of a seed abortion system, which specifically removes genetically incompetent SS homozygotes from the selfed progenies. It is likely that the original $\mathbf{N}$ containing $\bigcirc 6$ interchange heterozygotes did not have a seed-aborting system and that the system evolved gradually, removing progressively larger proportions of the SS homozygotes. The nascent complex heterozygotes may well have had incomplete seed-aborting systems comparable to those of the present $06 \mathrm{~s}$ which permit some recovery of SS homozygotes. While it is possible that the leaky O6s which currently exist in the population are the direct products of slowly evolving autogamous nascent complex hybrid lineages, and the 7IIs their ancestors, it is more probable that the leaky $06 \mathrm{~s}$ and the 7IIs, which exhibit significant levels of seed abortion, are the products of sexual reproduction between divergent lineages and display a more primitive seed abortion phenotype more like that which would have been characteristic of their common ancestor.

Evidence presented above suggests that the seedaborting system is built on recessive lethal genes associated with the interchanged chromosomes of the $\mathbf{S}$ complex. In the case of the NS complex heterozygotes in which the $\mathbf{N}$ complex is not transmissible in the pollen, a single recessive lethal on the $\mathbf{S}$ complex would result in 50 per cent seed abortion. In the case of the naturally occurring 7IIs and the synthetic hybrids combining an $\mathbf{S}$ complex with an alethal ' 495 ' genome, a recessive lethal gene should result in 25 per cent seed abortion in selfed capsules. Any additional recessive lethals at independently assorting loci would increase the level of seed abortion. Seed abortion levels below 25 per cent indicate interactive genetic effects which must involve epistatic interactions between non-allelic genes as well as dominance relationships between alleles. While some of the epistasis may be due to genes determining gametic transmission levels, it is likely that the epistasis is mostly due to a more direct modification of $\mathbf{S}$ complex lethality by dominant genes at loci outside the interchange ring.
Because of the strict terminal localization of chiasmata in this material and the consequent aggregation of loci into supergenes, it is unlikely that detectable epistatic loci would show anything but independent assortment with $\mathbf{S}$ complex lethality. Thus, four independently assorting supergenic loci may modify $\mathbf{S}$ complex lethality. As there is no evidence that NS zygotes are included in the aborted seed, it would appear that the interchanged chromosomes of the $\mathbf{N}$ complex must carry a full array of the dominant modifiers of $\mathbf{S}$ complex lethality.

Recessive lethal genes and their dominant modifiers are readily modelled in terms of duplications and deficiencies. A chromosome segment deficiency, - a, may be regarded as a recessive lethal while the corresponding duplication, + a, may be regarded as a dominant modifier of that lethal. Transposition of the segment a from one chromosome to another site in the genome would generate a deletion, $-a$, in the source chromosome and a duplication, $+\mathrm{a}$, in the target. The homologue of the source chromosome, still carrying the segment a would be $+a$, while the homologue of the target chromosome, not receiving the segment a, would be $-\mathrm{a}$. Complex transpositional events creating a single deletion in the $\mathbf{S}$ complex and $n$ independently assorting duplications would create a seed abortion ratio of $(1 / 4)^{n+1}$. In the present case, segments could transfer from $\mathbf{S}$ to $\mathbf{N}$, which would give 50 per cent seed abortion, or to targets outside the ring and vice versa. Multiple transpositional events of this type may generate epistatic systems yielding seed abortion ratios of almost any magnitude.

Dominant modifiers of lethal genes have been demonstrated in other Isotoma complex hybrids (Lavery \& James, 1987) while evidence for relatively transposed chromosome segments has been adduced previously from the epistatic ratios associated with seed abortion in an 012 complex hybrid from Bencubbin (Beltran \& James, 1970). James (1970) also provided cytological evidence of internal segment transposition and proposed that recombination events occurring between homologous segments in otherwise non-homologous chromosomes may generate both the interchanges utilized in the formation of complex hybrid rings and, following Catcheside (1932, 1947), deletions used in the assembly of balanced lethal systems.

Kenton et al. (1987) have provided cytological evidence of the association of internal chromosome segment transposition and duplication with the evolution of complex hybridity in Gibasis pulchella and in their derivatives. These authors also reviewed similar evidence in other groups, including Calycadenia (Carr \& Carr, 1983), Antirrhinum (Ernst, 1940), rye (Levan, 
1942), wheat (Naronha-Wagner \& Mello-Sampayo, 1971) and Oenothera blandina (Catcheside, 1932, 1947).

Kenton et al. (1987) also raised the possibility that mobile genetic element activity may be associated with the generation of duplications and the extensive chromosome repatterning in Gibasis complex hybrids and elsewhere. Mobile genetic elements are ubiquitous devices which, in toto, generate an apparently comprehensive array of DNA sequence rearrangements (McClintock, 1978; Flavell et al., 1981; Shapiro, 1983; Freeling, 1984; Martin et al., 1988). While James (1970) postulated sequential interchanges involving different points in the same chromosome as a mechanism for generating the transpositions underlying the evolution of complex hybridity in Isotoma, transposition resulting from mobile genetic element activity may well be a more likely source of the evolutionary capability.

\section{Acknowledgements}

We would like to thank The University of Western Australia for its continuing support of this research and Mr David Waldie for horticultural assistance. We also thank the anonymous referees who provided constructive comments on the original manuscript.

\section{References}

BELTRAN, I. C. 1971. Embryology, balanced lethal systems and heterosis in Isotoma petraea. Ph.D Thesis, The University of Western Australia.

BELTRAN, I. C. AND JAMES, S. H. 1970. Complex hybridity in Isotoma petraea. III. Lethal system in $\bigcirc 12$ Bencubbin. Aust. J. Bot., 18, 223-232.

CARR, R. L. AND CARR, G. D. 1983. Chromosome races and structural heterozygosity in Calycadenia ciliosa Greene (Asteraceae). Am. J. Bot., 70, 744-755.

CATCHESIDE, D. G. 1932. The chromosomes of a new haploid Oenothera. Cytologia, 4, 68-113.
CATCheside, D. G. 1947. A duplication and a deficiency in Oenothera. J. Genet., 48, 99-110.

ERNST, H. 1940. Zytogenetische Untersuchungen an haploiden Pflanzen von Antirrhinum majus. 1. Die Meiosis. Z. Bot., 35, 161-190.

FLAVELL, R. B., O'DELL, M. AND HUTCHINSON, J. 1981. Nucleotide sequence organization in plant chromosomes and evidence for sequence translocation during evolution. Cold Spring Harbor Symp. Quant. Biol., 45, 501-508.

FREELING, M. 1984. Plant transposable elements and insertion sequences. Ann. Rev. Plant Physiol., 35, 277-298.

JAMES, S. H. 1965. Complex hybridity in Isotoma petraea. I. The occurrence of interchange heterozygosity, autogamy and a balanced lethal system. Heredity, 20, 341-353.

JAMES, S. H. 1970. Complex hybridity in Isotoma petraea. II. Components and operation of a possible evolutionary mechanism. Heredity, 25, 53-77.

JAMES, S. H., WYLIE, A. P., JOHNSON, M. S., CARSTAIRS, S. A. AND SIMPSON, G. A. 1983. Complex hybridity in Isotoma petraea. V. Allozyme variation and the pursuit of hybridity. Heredity, 51, 653-663.

JAMES, S. H., SAMPSON, J. F. AND PLAYFord, J. 1990. Complex hybridity in Isotoma petraea. VII. Assembly of the genetic system in the $\bigcirc 6$ Pigeon Rock population. Heredity, 64 , 289-295.

KENTON, A., DAVIES, A. AND JONES, K. 1987. Identification of Renner complexes and duplications in permanent hybrids of Gibasis pulchella (Commelinaceae). Chromosoma, 95, 424-434.

LAVERY, P. AND JAMES, S. H. 1987. Complex hybridity in Isotoma petraea. VI. Distorted segregation, gametic lethal systems and population divergence. Heredity, 58, 401-408.

LEVAN, A. 1942. Studies on the meiotic mechanism of haploid rye. Hereditas, 28, 177-211.

MCCLINTOCK, B. 1978. Mechanisms that rapidly reorganize the genome. Stadler Genet. Symp., 10, 25-48.

MARTIN, C., MACKAY, S. AND CARPENTER, R. 1988. Large-scale chromosomal restructuring is induced by the transposable element Tam 3 at the nivea locus of Antirrhinum majus. Genetics, 119, 171-184.

NARONHA-WAGNER, M. AND MELLO-SAMPAYO, T. 1971. Haploids nulli 5B of Triticum aestivum. Agron. Lusit., 33, 315-322.

Shapiro, J. A. (ed.), 1983. Mobile Genetic Elements. Academic Press, New York. 